\title{
Future Scenarios as a Research Tool: Investigating Climate Change Impacts, Adaptation Options and Outcomes for the Great Barrier Reef, Australia
}

\author{
Louisa S. Evans • Christina C. Hicks • Pedro Fidelman • \\ Renae C. Tobin • Allison L. Perry \\ Published online: 24 August 2013 \\ (C) The Author(s) 2013. This article is published with open access at Springerlink.com
}

\begin{abstract}
Climate change is a significant future driver of change in coastal social-ecological systems. Our knowledge of impacts, adaptation options, and possible outcomes for marine environments and coastal industries is expanding, but remains limited and uncertain. Alternative scenarios are a way to explore potential futures under a range of conditions. We developed four alternative future scenarios for the Great Barrier Reef and its fishing and tourism industries positing moderate and more extreme $\left(2-3{ }^{\circ} \mathrm{C}\right.$ above pre-industrial temperatures) warming for 2050 and contrasting 'limited' and 'ideal' ecological and social adaptation. We presented these scenarios to representatives of key stakeholder groups to assess the perceived viability of different social adaptation options to deliver desirable outcomes under varied contexts.
\end{abstract}

Keywords Adaptation · Future scenarios · Coastal ecosystems · Governance $\cdot$ Fishing $\cdot$ Tourism $\cdot$ Great Barrier Reef $\cdot$ Australia

Electronic supplementary material The online version of this article (doi:10.1007/s10745-013-9601-0) contains supplementary material, which is available to authorized users.

L. S. Evans $(\bowtie) \cdot$ C. C. Hicks

Australian Research Council Centre of Excellence for Coral Reef Studies, James Cook University, Townsville, Queensland, Australia e-mail: Louisa.evans@jcu.edu.au

C. C. Hicks

School of Business, James Cook University, Queensland, Australia

P. Fidelman

Sustainability Research Centre, University of the Sunshine Coast, Queensland, Australia

R. C. Tobin

Centre for Sustainable Tropical Fisheries and Aquaculture,

School of Earth of Environmental Sciences, James Cook

University, Townsville, Queensland, Australia

e-mail: renae.tobin@jcu.edu.au

A. L. Perry

Oceana, C/Leganitos, 47, 28013 Madrid, Spain

\section{Introduction}

Coastal and marine ecosystems provide more benefits to society than many other social-ecological systems (MA 2005a). Climate change is identified as one of the most profound future drivers of change in these systems, encompassing both risk and potential opportunity (Hughes et al. 2003; Hoegh-Guldberg and Bruno 2010; Pereira et al. 2010). Research into climate change impacts, experiences of adaptation, and projected outcomes for marine environments and coastal industries continues to build knowledge and consensus around our climate change future, e.g., the Intergovernmental Panel on Climate Change (IPCC) $4^{\text {th }}$ assessment (2007). However, impacts, responses, and outcomes are location specific; dependent on how global climate change manifests at regional and local scales and on the vulnerability of the regional, national, and local contexts to these changes (McClanahan et al. 2008; Allison et al. 2009; Bjarnadottir et al. 2011). There is considerable uncertainty about the impacts of climate change for different places and people over time.

In the Great Barrier Reef(GBR) World Heritage Area and Marine Park in Australia, climate change impacts are already evident. Mass coral bleaching was experienced in 1998, 2002, and 2006 in the southern GBR, and sea level rise and ocean acidification have been documented (Hoegh-Guldberg and Hoegh-Guldberg 2004; GBRMPA 2009a; Lough 2012). Ongoing, the GBR region will be affected by air and sea temperature increases, sea level rise, higher concentrations of $\mathrm{CO}_{2}$, changing rainfall patterns, and increased intensity of storm events when they occur (their frequency is not expected to change) (Lough 2007). Climate change represents the top threat to the reef with major implications for its ecological, economic, and sociocultural values (Johnson and Marshall 2007; Wachenfeld et al. 2007). Adaptation to climate change is therefore, at the forefront of research, policy, and management of the region, although strategies and plans are 
still broad to account for uncertainty over changing perceptions of climate change.

We present four alternative scenarios to explore multiple perspectives on climate change impacts, adaptation options, and potential outcomes, using the GBR's commercial and recreational fishing and reef-based tourism industries as a case-study. Alternative scenarios are plausible descriptions of how the future may unfold (IPCC 2000; MA 2005b) used to scope potential outcomes resulting from different human responses under a range of conditions. They present different choices and suggest potential outcomes resulting from these choices (e.g., Bohnet et al. 2008; Bohensky et al. 2011). We use scenarios as a research tool to provide a unique analysis of how stakeholders frame adaptation choices within the context of future 'realities'.

Most scenario exercises to date focus on modelling climate change trends and/or impacts (Hulme and Dessai 2008). Increasingly, they are also used to articulate adaptation responses at different scales, from global to local. Typically, scenarios are developed as an end in themselves, for example, the IPCC emissions scenarios (IPCC 2000) and the Millennium Ecosystem Assessment scenarios (MA 2005b). This can occur through expert-driven, scientific processes (Bohensky et al. 2011) or through multi-stakeholder policy and action research processes where the learning that occurs throughout scenario development is as important as the final scenarios (Wollenberg et al. 2000; Tompkins et al. 2008; Cobb and Thompson 2012; Haward et al. 2012; Johnson et al. 2012). Alternatively, scenarios can be used as a tool to identify future actions. As described by Wilby and Dessai (2010) scenarios are used widely in vulnerability and risk assessment exercises to inform impact models from which scientists, managers and/or resource-users identify adaptation strategies to minimise risk. This often occurs within an adaptation policy and planning context (e.g., the risk and vulnerability assessments underway in Queensland's farming and fishing industries; Brundell et al. 2010). Rarely do these processes go on to appraise, evaluate, or implement the adaptation strategies identified (Wilby and Dessai 2010).

Here, we take a similar approach to risk assessment in that our scenarios are not the end goal but a research (as opposed to planning) tool to elicit further information. They provide a future 'vulnerability context' that frames in-depth qualitative data collected on industry adaptation experiences and expectations. We thereby place considerable emphasis on understanding stakeholders' perceptions of a range of adaptation strategies contextualised within the four alternative futures. As Wollenberg et al. (2000: 66) note, using scenarios can stimulate "creative ways of thinking that help stakeholders break out of established patterns of assessing situations." Our scenarios contrast moderate and more extreme climate change trends, set against two contrasted adaptation strategies: limited and ideal. They allow us to explore stakeholders' perceptions of: i) different adaptation strategies within four different ecological and social impact contexts, and ii) projected ecological and social outcomes based on contrasted ideal and limited adaptation pathways.

After detailing our methodology we present our four scenarios. We then explore the diversity of stakeholder responses to them and highlight the adaptation strategies and outcomes that were valued in the fishing and tourism sectors. We conclude with a discussion of the utility of scenarios as a research tool for understanding experiences and perceptions of adaptation.

\section{Methods}

Framing the Scenarios

We framed our four scenarios around two climate change trends for 2050 - a best-case and worst-case situation - and two contrasted adaptation pathways - ideal and limited ecological and social adaptation (Fig. 1). This framework allowed us to investigate how adaptation could play out under a range of potential ecological and social impacts. Under best-case climate change trends, air temperatures rise by less than $1.5^{\circ} \mathrm{C}$ above 1990 levels $\left(2{ }^{\circ} \mathrm{C}\right.$ above the preindustrial average) and in the worst-case, air temperatures rise by more than $2.5^{\circ} \mathrm{C}$ above 1990 levels $\left(3{ }^{\circ} \mathrm{C}\right.$ above the pre-industrial average). These projections were adapted from the GBR Marine Park vulnerability assessment (Johnson and Marshall 2007), and align with the regional climate projections developed by the Queensland Climate Change Centre of Excellence (QCCCE n.d.). Ecological, institutional, and economic limits constrain strategies under the limited adaptation scenario (Adger et al. 2007). Ideal adaptation is not limited by these factors, ${ }^{1}$ and is most effective at reducing vulnerability to climate change.

\section{Developing Plausible Alternative Storylines}

We conducted a systematic literature review and broad scientific elicitation to develop our four storylines framed around the axes described above. The literature review consolidated existing knowledge of climate change trends, impacts, adaptation, and potential outcomes in the GBR region. We used the ISI Web of Knowledge to conduct three distinct searches to compile literature related to: i) climate change trends and impacts; ii) adaptation responses, and; iii) limits to adaptation in the GBR, Queensland, or Australia. We reviewed a total of 253 articles in full (see Supplementary material). For the scientific elicitation, we asked scientists working on climate change in Australia to complete a semistructured scenario response template that presented information on temperatures, ocean acidification, rainfall patterns, and

\footnotetext{
${ }^{1}$ Ecological adaptation thresholds still apply but are more optimistic.
} 


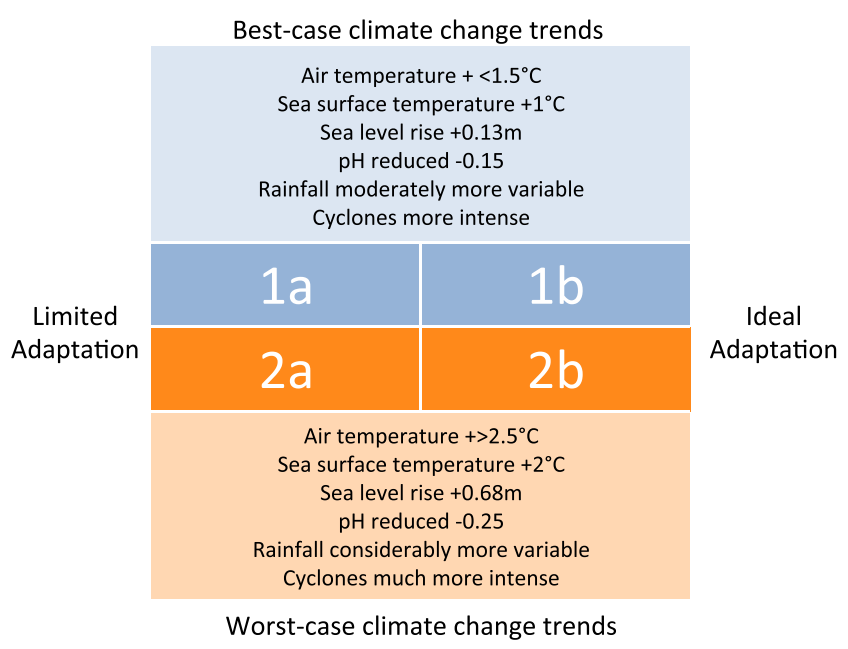

Fig. 1 Scenario framework presenting climate change trends for 2050 along the vertical axis and alternative adaptation pathways along the horizontal axis

extreme events under the moderate and extreme climate change trends for 2050 (Fig. 1; http://dl.dropboxusercontent.com/u/ 9744348/Scenario_template.pdf). Respondents were asked to outline potential ecological and social impacts from these trends, followed by possible adaptation strategies under a limited and ideal situation. We contacted a broad, 'non-selective' sample of scientists and received 27 comprehensive responses to our scenario template. Some were group responses, compiled following brainstorming meetings. Others provided information in the form of papers and project reports, which we included in the literature review. Fish, coral, mangrove, seagrass, turtle, and sea snake specialists, agricultural scientists, environmental engineers, planners, economists and social scientists working on fishing, tourism, agriculture and coastal development responded to the scientific elicitation process. Three project investigators coded the responses and the most frequent trends were combined with information from the literature review to form the alternative storylines. The scenarios focused on the reef, recreational and commercial fishing, and reef-based tourism. Agriculture and coastal development were included, but only where relevant to fishing and tourism.

\section{Eliciting Data on Social Adaptation}

We conducted a series of workshops and interviews with GBR stakeholders $(n=26)$ to elicit data on industry adaptation experiences and expectations. Representatives of local and state government, fishing and tourism industries, the non-government sector, and research institutions participated in this research phase. Every effort was made to include a wide range of organisations (see Supplementary material).

First, the four alternative scenarios were presented to participants. In open-ended but facilitated discussion, participants were then asked to reflect on the scenarios and compare the impact-adaptation-outcome storylines to their knowledge and experience of change in the region, and their expectations for the future. Specifically we wanted to understand: i) whether participants thought the broad, regional scenarios were plausible for different parts of the GBR; ii) whether the adaptation strategies outlined in the scenarios were feasible, possible for different groups of people, and likely to be effective in reducing vulnerability to the range climate change impacts outlined, and; iii) what adaptation outcomes participants valued and whether or not these would be achievable under the different scenarios. Through facilitated discussion we focused first on broad reflections on the scenarios, then on desirable adaptation outcomes, and finally we systematically considered five broad categories of adaptation strategies in turn. These emerged in the literature review and scientific elicitation as important potential adaptation strategies, and include Business planning; Diversification; Effort management; Mobility and migration; and Stewardship. Participants identified and discussed specific adaptation actions within these broad classifications. In general, our approach was exploratory; we did not expect participants to strictly differentiate between each of the four scenarios when sharing their views on adaptation. Instead, the scenarios provided a broad future vulnerability context (different from the current status of the reef) that participants could draw on to explain or frame their perceptions. We digitally recorded and transcribed data, which were coded by three project investigators using QSR Nvivo v9.

Our results present the original scenarios as developed through the expert elicitation and literature review: we did not change the scenarios based on participant stakeholders' perceptions. We then highlight areas of convergence and divergence among the scenarios and stakeholders' views on climate change, not to compare scientific and lay knowledge but to investigate what understandings and motivations underlie stakeholders' views on adaptation. We believe this offers unique insight into how coastal stakeholders frame adaptation choices within the context of future 'realities.'

A final workshop was held in Brisbane on 12th August $2011(n=7)$ to disseminate research findings to policy makers and managers. In total, over 60 people representing industry, government, and the scientific community participated in this study either inputting or responding to the scenarios.

\section{Results}

From the systematic literature review and scientific elicitation we outline, below, the scientific evidence for the alternative scenarios ${ }^{2}$ (Fig. 2).

\footnotetext{
${ }^{2}$ The scenarios for the GBR and its fishing and tourism industries are available in full at $\mathrm{http} / / / \mathrm{dl}$.dropboxusercontent.com/u/9744348/ Limits_to_CCA_in_the_GBR.pdf.
} 


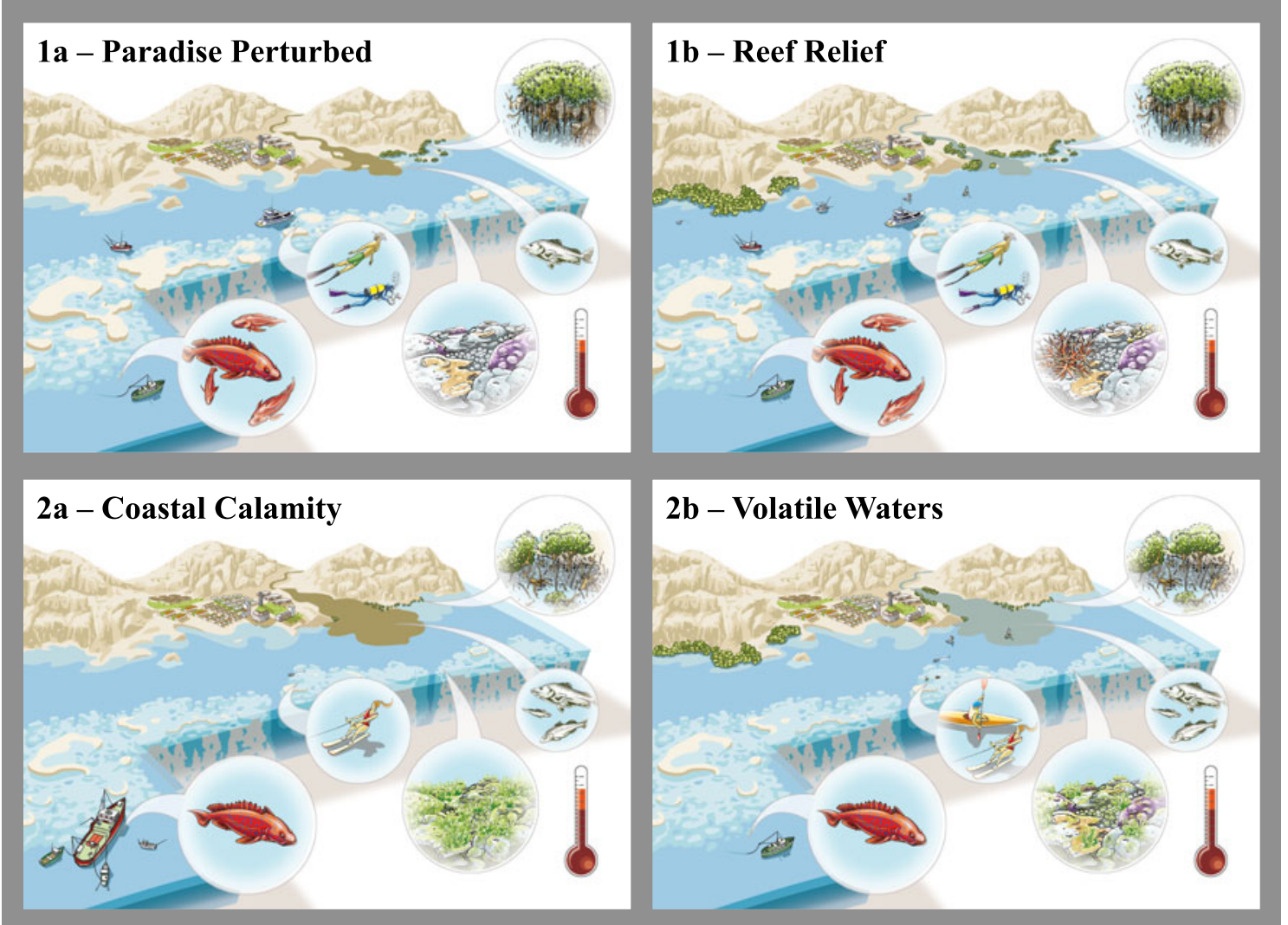

Fig. 2 Four alternative future scenarios for the Great Barrier Reef to 2050 under moderate ( $1 \mathrm{a}$ and $1 \mathrm{~b})$ and extreme $(2 \mathrm{a}$ and $2 \mathrm{~b})$ climate change, and limited (1a and $2 a)$ and ideal ( $1 \mathrm{~b}$ and $2 \mathrm{~b}$ ) adaptation. The scenarios reflect key differences in run-off from the catchment and

\section{Climate Change Impacts by 2050}

The impacts of moderate (best-case) and more extreme (worstcase) climate change trends are summarised in Table 1. Current exposure to climate variability; extreme events such as the 1998 and 2002 temperature anomalies and bleaching; and Tropical Cyclones Hamish and Yasi illustrate the potential consequences of moderate climate change impacts on the region's coastal ecosystems (see Supplementary material for references on impacts from distinct drivers on corals, fish and mangroves). For more extreme impacts, exposure to extreme climatic events, laboratory experiments on the responses of marine organisms to environmental stress including increased temperature and acidification (e.g., Munday et al. 2009; Nilsson et al. 2012), and models of environmental change driven by future climates (e.g., Hoegh-Guldberg et al. 2007; Bohensky et al. 2011; Fulton 2011) can inform projections of potential ecological effects.

Research suggests that even under a moderate, best-case climate scenario, combinations of warmer ocean temperatures, acidification, and increased disturbance events will alter coral reef and coastal habitats. In particular, we will see changes in coral cover, species composition, fish distribution and possibly water quality, coral cover and composition, mangrove erosion and distributional change, fish abundance (illustrated by coral trout and barramundi) and social adaptation in the fishing and tourism industries. Artwork by Pinillos, 2011

abundance, with subsequent implications for productivity and diversity (e.g., Hoegh-Guldberg et al. 2007; Gilman et al. 2008; Munday et al. 2008; Anthony et al. 2012). Reef-dependent and reef-associated fish species will likely be most negatively affected by climate-induced changes. Productivity of other fisheries may increase, or fluctuate with weather patterns (e.g., rainfall dependent species) although on the whole, declines in primary productivity or prey availability may negate benefits from growth (Robins et al. 2005; Hobday et al. 2008; Munday et al. 2008; Gillson 2011).

Under more extreme climate change trends, studies suggest that the rapid rates of change and the increased incidence of disturbance events would significantly reduce the resilience of coral reefs and increase the prospect of phase shifts from coral to algal dominance (even with high herbivory and low nutrient inputs) (Anthony et al. 2012; Thomas et al.2012). With potentially widespread phase shifts to algal dominance, reef-dependent fish species would decline significantly or be lost, reef-associated marine organisms would be heavily impacted (Munday et al. 2008), and the aesthetics of the reef would be substantially altered. Pandolfi et al. (2011) argue that research into historical responses of coral reefs to climate change suggests that effects over the next few 
Table 1 Climate change trends affecting the Great Barrier Reef under different scenarios by 2050

\begin{tabular}{|c|c|}
\hline Moderate climate change trends & Extreme climate change trends \\
\hline Impacts on coral reef ecosystems include: & Impacts on coral reef ecosystems include: \\
\hline - increased incidence of temperature anomalies & - markedly increased incidence of temperature anomalies \\
\hline - increased exposure of coral reefs to freshwater run-off in wet seasons & - increased exposure of coral reefs to freshwater run-off in wet seasons \\
\hline - moderate increases in cyclone damage & - substantial increases in cyclone damage \\
\hline - more frequent outbreaks of pests and diseases on corals & - more frequent and extensive outbreaks of pests and diseases on corals \\
\hline - mild ocean acidification effects & - moderate ocean acidification effects. \\
\hline Impacts on other coastal ecosystems include: & Impacts on other coastal ecosystems include: \\
\hline \multirow[t]{2}{*}{$\begin{array}{l}\text { - increased erosion from both sea-level rise and more intense } \\
\text { cyclones. }\end{array}$} & $\begin{array}{l}\text { - significantly increased erosion from both sea-level rise and more intense } \\
\text { cyclones, }\end{array}$ \\
\hline & $\begin{array}{l}\text { - increased exposure to more extreme environmental conditions related to } \\
\text { flooding and drought events. }\end{array}$ \\
\hline \multirow{3}{*}{$\begin{array}{l}\text { Direct impacts on fish relate to: } \\
\text { - warming sea temperatures. }\end{array}$} & Direct impacts on fish relate to: \\
\hline & • warming sea temperatures, \\
\hline & • increased exposure to pulses of freshwater. \\
\hline $\begin{array}{l}\text { Impacts are projected to be localized, i.e., felt in different places at } \\
\text { different times. }\end{array}$ & Impacts are projected to be widespread and extend to deeper waters. \\
\hline
\end{tabular}

decades are likely to be more variable in time and space than most current projections. Nevertheless, many quantitative modelling scenarios indicate that under worstcase climate scenarios drastic changes to coral reef habitats and potential collapse are possible by 2050 (Hoegh-Guldberg et al. 2007; Baskett et al. 2009; Bohensky et al. 2011; Thomas et al. 2012). Other than habitat alteration, more rapid and extreme climate change would mean more severe sub-lethal and lethal effects on fish and other marine organisms, particularly on more vulnerable early life-stages (Munday et al. 2008). There are also greater implications for distributional shifts of marine organisms.

\section{Ecological Adaptation and Outcomes}

The potential for ecological adaptation of coastal ecosystems and marine organisms remains highly uncertain; dependent on the magnitude and rate of climate change, the resilience of the reef environment, and species-specific traits (Pandolfi et al. 2011). Some argue that the rates of change under both moderate and extreme scenarios exceed historic rates of change and, therefore, are likely to overwhelm the capacity for ecological adaptation or acclimation in most marine organisms. This is particularly so with heat-resistant corals (Hoegh-Guldberg 1999; Hoegh-Guldberg et al. 2007). Others suggest that under certain conditions, adaptation of corals and fish may be possible with moderate climate change trends (Munday et al. 2008; Baskett et al. 2009; Miller et al. 2012). Fish species with geographical ranges that span large temperature gradients or with relatively short re-generation times are more likely to adapt fast enough to moderate climate change impacts. However, adaptation of marine organisms to habitat degradation is unlikely (Munday et al. 2008). Finally, some fish species and habitat types may adapt through distributional range shifts (Perry et al. 2005; Hobday et al. 2006; Gilman et al. 2008; Hobday 2011; Traill et al. 2011). It is unlikely, however, that coral reef fishes will be found at higher latitudes than current distributions (Munday et al. 2008) or that corals and reef-associated fish would shift significantly (Hoegh-Guldberg et al. 2007).

Considering both moderate and extreme climate change trends, and optimistic versus limited scope for ecological adaptation, our alternative future scenarios suggest four trajectories of ecological change (Table 2).

\section{Social Adaptation and Outcomes}

Local to regional management of coastal ecosystems can potentially minimise the environmental impacts of climate change (Bohensky et al. 2011). Similarly, social adaptation can mediate the direct and indirect impacts of climate change on society (Adger et al. 2005). People's experiences of managing and adapting to long-term environmental change (e.g., declining fish stocks), climate fluctuations (e.g., seasonal and inter-annual variability in resource availability), climatic extremes (floods, droughts, cyclones), and other extreme events (e.g., tsunamis, conflict, economic crises) can illustrate the potential of particular strategies to reduce vulnerability or risk and to capture new opportunities. In the scenarios we posit that under moderate climate change (scenarios 1a and $1 \mathrm{~b}$ ) the changes to coastal 
Table 2 Four alternative future scenarios on ecological change in the Great Barrier Reef by 2050

\begin{tabular}{|c|c|}
\hline & Limited adaptation \\
\hline \multirow{10}{*}{$\begin{array}{l}\text { Moderate climate } \\
\text { change trends } \\
\text { (best-case) }\end{array}$} & 1a) Paradise Perturbed \\
\hline & Reefs remain in a coral-dominated state: \\
\hline & $\begin{array}{l}\text { - Coral cover declines and composition shifts to more heat- } \\
\text { resistant massive and encrusting species (e.g., Porites spp). }\end{array}$ \\
\hline & $\begin{array}{l}\text { - As impacts are localised, refuges of heat-sensitive staghorn, } \\
\text { branching and table corals allow some recovery. }\end{array}$ \\
\hline & $\begin{array}{l}\text { - Mild ocean acidification effects on coral growth hinder } \\
\text { recovery. }\end{array}$ \\
\hline & Ecological adaptation of coastal habitat is constrained: \\
\hline & $\begin{array}{l}\text { - Coastal habitats, like mangroves, cannot easily shift } \\
\text { shoreward, upstream and southward. }\end{array}$ \\
\hline & - Coastal habitats experience a slight decline in cover. \\
\hline & $\begin{array}{l}\text { Habitat changes affect dependent species, including reef fish, } \\
\text { turtles and sea-birds: }\end{array}$ \\
\hline & $\begin{array}{l}\text { - Reef function is maintained although marine biodiversity } \\
\text { declines. }\end{array}$ \\
\hline
\end{tabular}

Direct climate change impacts on fish are moderate:

- Some species (e.g., coral trout) to shift their distribution southward and into deeper waters.

Extreme climate change trends (worst-case)
Ideal adaptation

\section{1b) Reef Relief}

Reefs remain in a coral-dominated state:

- Coral cover is high and is comprised of heat-sensitive and more heat-resistant species

- Coral mortality in heat-sensitive corals is lower than expected due to ecological adaptation.

- Refuges of heat sensitive corals and improved water quality foster recovery of reefs.

- Mild ocean acidification effects on coral growth hinder recovery.

Ecological adaptation of coastal habitat is facilitated:

- Coastal habitats, like mangroves and beaches shift shoreward, upstream and southward.

- Overall cover is maintained.

Marine animals adapt to these moderate changes in reef and coastal habitat:

- Reef function and overall biodiversity are maintained.

- Composition and distribution of marine environments are altered.

Direct climate change impacts on fish are moderate:

- Some species to shift their distribution southward and into deeper waters.

\section{2b) Volatile Waters}

Reefs tend towards a state of flux, shifting between coral and algal-dominance:

- Coral mortality is lower than expected in more heatresistant corals (e.g., Porites spp).

- A few refuges of primarily massive and encrusting corals remain on mid-shelf and outer reefs.

- Large-scale recovery is undermined by the frequency and intensity of disturbance events.

- Moderate ocean acidification slows coral growth and undermines reef structure.

Ecological adaptation of coastal habitat is constrained:

- Coastal habitats cannot shift shoreward, upstream and southward.

Ecological adaptation of coastal habitats is facilitated:

- Coastal habitats shift shoreward, upstream and southward.

- Chronic erosion and more variable water availability reduce overall habitat cover.

- Shoreline erosion is exacerbated.

Habitat changes affect dependent species, including reef fish, turtles and sea-birds:

- Many of the essential functions of the reef are lost.

Direct climate change impacts on fish are significant:

- Warmer temperatures cause some species (e.g., coral trout) to shift their distribution southward and into deeper waters.
Some marine species adjust to compositional and distributional changes in reef and coastal habitat:

- Yet, many organisms dependent on these habitats (e.g., damselfish) decline significantly.

- The essential functions of the reef are maintained periodically and in patches.

- Overall marine biodiversity declines significantly.

Direct climate change impacts on fish are significant:

- Negatively impact the growth and productivity of many species, though some pelagic species benefit. 
Table 2 (continued)

\begin{tabular}{lc}
\hline Limited adaptation & Ideal adaptation \\
\hline $\begin{array}{l}\text { Warming also negatively impacts the growth and productivity } \\
\text { of many species, though some pelagic species (e.g., trevally) } \\
\text { benefit. }\end{array}$ & $\begin{array}{l}\text { • Bigger fluctuations in rainfall also cause numbers and } \\
\text { distributions of rainfall-dependent species to vary } \\
\text { considerably. }\end{array}$ \\
$\begin{array}{l}\text { Bigger fluctuations in rainfall cause numbers and distributions } \\
\text { of rainfall-dependent species (e.g., barramundi) to vary } \\
\text { considerably. }\end{array}$ & \\
\hline
\end{tabular}

ecosystems and marine organisms reflect the variability experienced by reef-based industries from other drivers of change, including market fluctuations or regulatory change. Whereas under more extreme climate change (scenarios $2 a$ and $2 b$ ) the changes to coastal ecosystems and marine organisms present greater and longer lasting risks to reef-industries than other drivers of change. In the latter case previous experience of risk and adaptation may be limited in illustrating future outcomes (Adger and Barnett 2009). We draw on relevant regional research on varied adaptation strategies and the expert elicitation to deliberately counterpose 'limited' and 'ideal' adaptation strategies (Table 3). As such, our scenarios are speculative and do not reflect the current state of management and adaptation in the GBR.

In complex social-ecological systems, the ecological and social domains cannot be uncoupled. Thus, it is important to first account for how management and social adaptation can hinder or foster ecological adaptation, thereby influencing the nature of environmental change that the fishing and reef-based tourism industries would adapt to. Limited social adaptation under both moderate and extreme climate change trends (scenarios1a and 2a) exacerbate the detrimental impacts of climate change impacts (Table 2). For instance, reactive adaptation measures such as shading and coral transplantation, help only a few individual reefs (Hoegh-Guldberg et al. 2007), heavy fortification of coastlines prevents new coastal habitat from establishing (Gilman et al. 2008), and failure to change land use practices in the reef catchments means continued decline in water quality on the reef (McCulloch et al. 2003; Eberhard et al. 2009; Thomas et al. 2012). In the scenario Coastal Calamity nutrient loads in run-off reinforce the algal-dominated state of the reef (De'ath and Fabricius 2010). In contrast, with ideal adaptation, whether under moderate or extreme climate change (scenarios $1 \mathrm{~b}$ and $2 \mathrm{~b}$ ), the outlook for the reef is improved by integrated management of the catchment, reef and its fisheries (Hughes et al. 2010; Wooldridge et al. 2012), and rapid responses to bleaching events, cyclones, and predation outbreaks, combined with the use of technical solutions to protect vital coral refuges. Planned retreat of communities from the coast and effective habitat restoration also foster ecological adaptation of coastal habitats (Gilman et al. 2008).

Under the limited adaptation scenarios (1a and 2a), we suggest that climate change does not trigger major reorganisation within the fishing and tourism industries. Fishers respond to changes in availability of target fish species by increasing fishing effort, travelling further south and offshore, and using less selective fishing methods to diversify the catch (McClanahan and Cinner 2012). The tourism industry also responds by increasing effort, for instance, by fish-feeding and coral farming, concentrating effort on remaining coral refuges, travelling further south and offshore, and diversifying into other water-based activities. Flooded coastal infrastructure is abandoned and replaced elsewhere. Under more extreme climate change conditions (scenario $2 \mathrm{a}$ ) the commercial fishing industry is increasingly absorbed into large international corporations, which organise around off-shore ports and motherships to reduce travel time at sea while increasing effort. Similarly, under the guise of efficiency the tourism industry amalgamates into large corporations.

By contrast, where adaptation is effective the scenarios ( $1 \mathrm{~b}$ and $2 b$ ) suggest that stakeholders anticipate climate change and pursue planned, strategic adaptation. Adaptation in both the fishing and tourism industries includes: improving marine stewardship; improving business planning and forecasting; reducing effort (technology, time and capacity); migrating to different areas to relieve stress on vulnerable species or impacted sites; diversifying products, incomes and activities; and developing comprehensive emergency planning (GBRMPA 2009b; Gunn et al. 2010; Turton et al. 2010; Tobin et al. 2010; Cinner et al. 2012). Fisheries and tourism infrastructure are gradually retrofitted or relocated in response to sea-level rise (COAG 2009; DERM 2012). Under more extreme climate change conditions (Volatile Waters), the commercial fishing and tourism industries organise around co-operatives and the recreational fishers create linkages to these co-operatives. While ecological adaptation is largely overwhelmed by the rate and scale of change in Volatile Waters, management and social adaptation mediate, to the extent possible, the risks and opportunities created by climate change. 


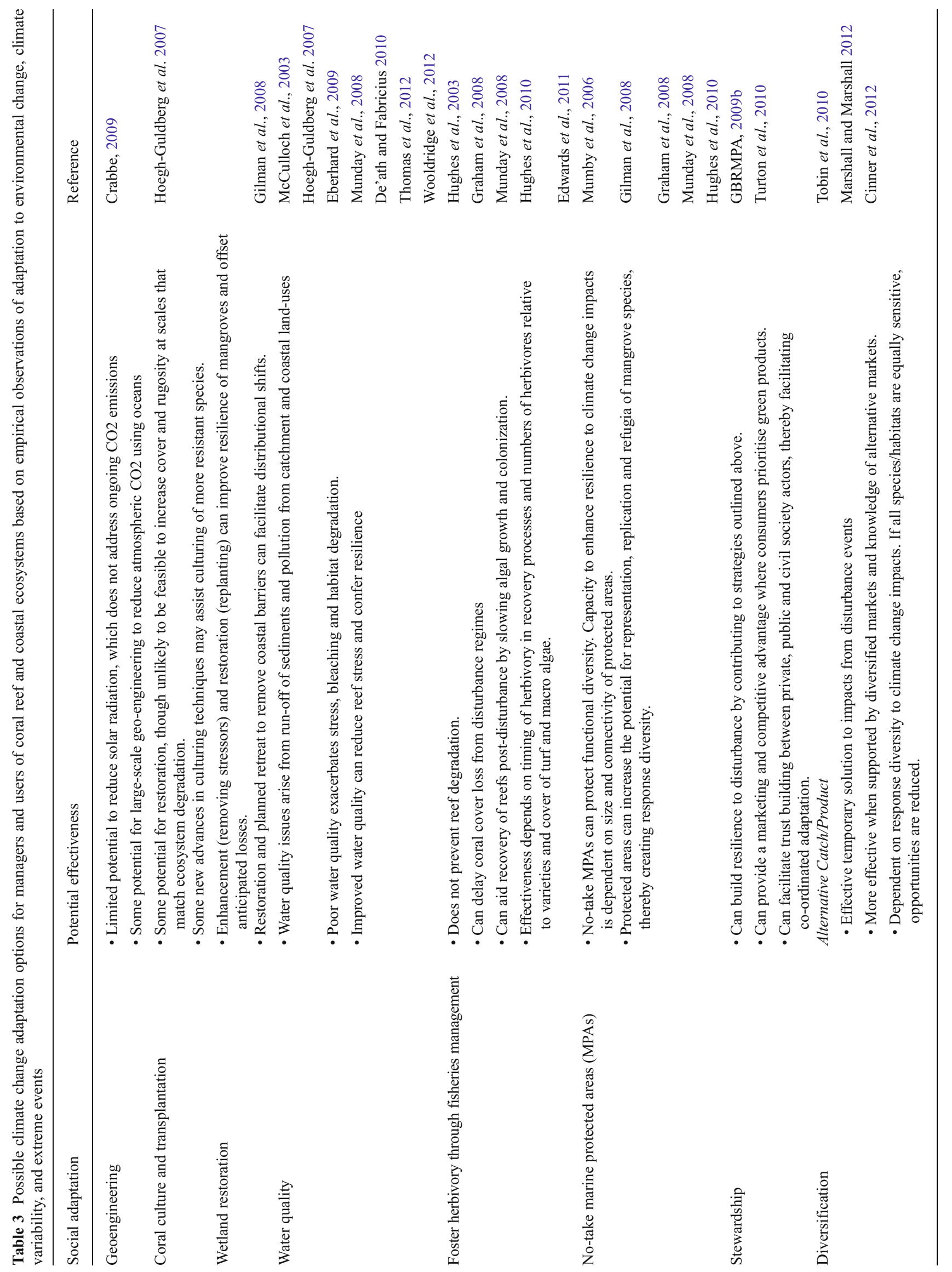




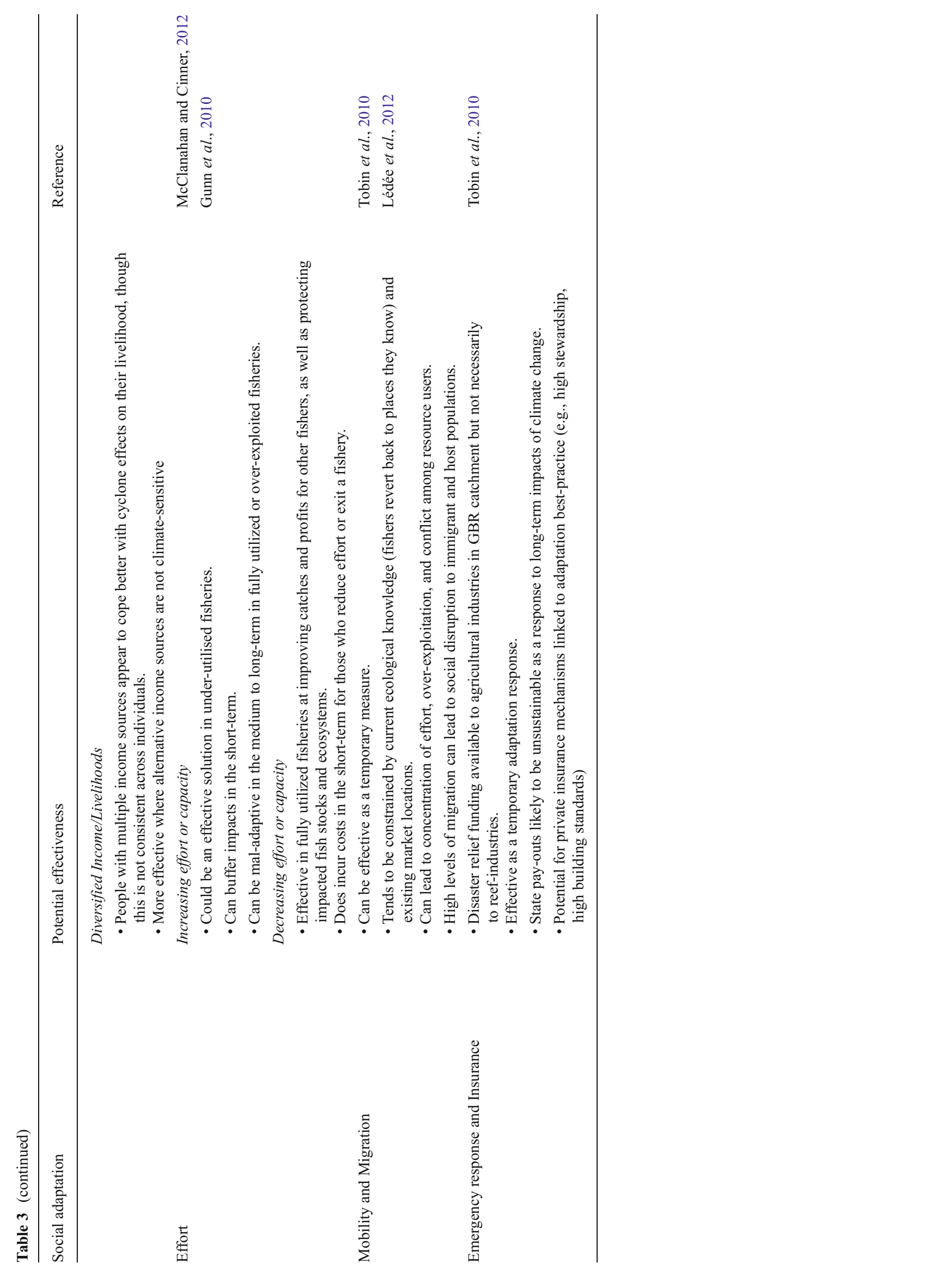


Building on the four ecological change storylines (Table 2), our scenarios posit a range of social outcomes from limited and effective management and social adaptation in the GBR (Table 4).

\section{Stakeholders' Perspectives on Adaptation}

This section highlights areas of convergence and divergence between the scenarios and stakeholder representatives' views of climate change impacts, social adaptation options and desirability of outcomes. These data emerged from the workshops and interviews.

Participants emphasised two overarching messages in reaction to the scenarios. First, the need to couch climate change adaptation research and planning in terms of opportunities in order to move forward and find solutions; participants highlighted that while changes to climate are not necessarily disputed, the rate of change, the capacity of individuals to mitigate and adapt to it, and the consequences for the reef and its industries remain contested. And some voiced concern over what they perceive as a general trend among the scientific and management community to represent climate change as overly negative. Second, participants noted that climate change is one of many challenges facing reef managers and industries, some of which are more immediate. They often shared experiences and examples that were related to other disturbances, such as the global financial crisis, fluctuations in the cost of energy, extreme weather events and other natural disasters, and regional security. Participants wanted the current spotlight on climate change to enhance rather than detract from attention to other issues in the GBR region.

\section{Views on Ecological Impacts and Environmental} Governance

Overall, participants associated a high level of uncertainty with the ecological impacts of climate change on the GBR. Tourism and commercial fishing representatives saw climate change as a key driver of change in the region but tended to align more closely with the moderate climate change scenarios (1a and 1b). For instance, they focused on variable or localised

Table 4 Four alternative future scenarios on social change in the Great Barrier Reef by 2050

\begin{tabular}{|c|c|c|}
\hline & Limited adaptation & Ideal adaptation \\
\hline \multirow{7}{*}{$\begin{array}{l}\text { Moderate climate } \\
\text { change trends } \\
\text { (best-case) }\end{array}$} & 1a) Paradise Perturbed & 1b) Reef Relief \\
\hline & $\begin{array}{l}\text { Commercial fishing and reef-based tourism sectors can remain } \\
\text { profitable for many, though some operators may exit. }\end{array}$ & $\begin{array}{l}\text { The new visions and strategies of reef industries effectively } \\
\text { offset impacts and improve the outlook for the GBR. }\end{array}$ \\
\hline & $\begin{array}{l}\text { Recreational fishers can also continue to enjoy the cultural } \\
\text { services of the reef. }\end{array}$ & $\begin{array}{l}\text { Commercial fishing and reef-based tourism sectors can remain } \\
\text { profitable. }\end{array}$ \\
\hline & $\begin{array}{l}\text { Overall, sustainability of the reef and its fisheries would } \\
\text { decline. }\end{array}$ & $\begin{array}{l}\text { Recreational fishers can also continue to enjoy the cultural } \\
\text { services of the reef. }\end{array}$ \\
\hline & $\begin{array}{l}\text { Conflict between managers, commercial and recreational } \\
\text { fishers, and tourism operators would increase slightly. }\end{array}$ & Sustainability of the reef is improved. \\
\hline & $\begin{array}{l}\text { Non-climate drivers of change such as market prices, energy } \\
\text { costs, and regulation continue to be of great importance to all } \\
\text { sectors. }\end{array}$ & Conflict between stakeholders is reduced. \\
\hline & & $\begin{array}{l}\text { Adapting to climate change furnishes reef sectors with } \\
\text { capacity to adapt to other non-climate drivers of change, } \\
\text { which continue to be significant. }\end{array}$ \\
\hline \multirow{6}{*}{$\begin{array}{l}\text { Extreme climate } \\
\text { change trends } \\
\text { (worst-case) }\end{array}$} & 2a) Coastal Calamity & 2b) Volatile Waters \\
\hline & $\begin{array}{l}\text { Reef-based industries would no longer be profitable and many } \\
\text { independent operators would be forced to exit these } \\
\text { industries. }\end{array}$ & $\begin{array}{l}\text { Even with ideal adaptation extreme climate change will mean } \\
\text { that reef-based industries are less profitable. }\end{array}$ \\
\hline & $\begin{array}{l}\text { Some recreational fishers might continue to fish but would } \\
\text { likely receive far less enjoyment from the cultural services of } \\
\text { the reef; many would choose to fish elsewhere. }\end{array}$ & $\begin{array}{l}\text { Anticipating this, many operators exit reef industries } \\
\text { voluntarily. Given this, the industries can be viable for the } \\
\text { few who remain and adapt. }\end{array}$ \\
\hline & Sustainability of the reef's fisheries would also decline. & $\begin{array}{l}\text { Recreational fishers might continue to fish but would likely } \\
\text { combine fishing with other leisure activities in order to } \\
\text { maintain enjoyment from the varied cultural services of the } \\
\text { reef. }\end{array}$ \\
\hline & $\begin{array}{l}\text { Conflict between managers, commercial fishers, and } \\
\text { recreational fishers would increase dramatically. }\end{array}$ & Sustainability of the GBR would be an ongoing challenge. \\
\hline & $\begin{array}{l}\text { With limited adaptation, many lifestyle values associated with } \\
\text { reef-based industries are lost. }\end{array}$ & $\begin{array}{l}\text { Collaboration between stakeholders could be strengthened by } \\
\text { the common problem. }\end{array}$ \\
\hline
\end{tabular}


impacts across the vast and diverse geography of the +2900 reefs of the GBR stretching from north to south, they discussed compositional shifts in corals rather than phase shifts to algal reefs, and they challenged the notion of significant losses of coastal habitat, such as mangroves from climate change as opposed to coastal development. A tourism industry representative countered the scenarios under more extreme climate change (in particular 2a):

I'm buoyed by the fact that the reef isn't going to disappear, it's going to change. (March 2011)

Representatives of the recreational fishing sector suggested that recreational fishers do not generally perceive a problem adapting to the direct impacts of climate change, only to the adaptation actions of other stakeholders, including managers:

We can adapt to climate change but it's going to be increasingly difficult for us to adapt to some of the other changes that are forced on us.

(Recreational fishing representative, April 2011)

In terms of environmental governance, participants identified coastal development and catchment land-use practices as the primary threats to reef resilience and both ecological and social adaptive capacity. The current political focus on climate change was seen as a key opportunity to reorganise how the GBR catchment and coastline are valued and managed. Participants suggested that really effective management and adaptation in the catchment and coastline - including protection and rehabilitation of mangrove habitat around the Trinity Inlet, Hinchinbrook Channel and the Fitzroy River, for example - could substantially improve the outlook for GBR ecosystems and industries despite climate change (as reflected under 'ideal' adaptation in 1b). However, it was recognised that this opportunity could require significant changes in other industries, including sugar cane farming, cattle production, and property development. For participants, government subsidies to agricultural industries and current demographic trends in the region indicate that transformation of catchment industries and coastal development trajectories is extremely unlikely.

With regards to more conventional reef management, participants argued for a more dynamic approach to spatial management that could respond to environmental change triggered by climate change, such as species and habitat distribution shifts, and to the changing vulnerabilities of the GBR industries. Participants discussed positive examples of situations where fishing or tourism operators were permitted to access alternative sites, temporarily, when their usual grounds were impacted by flooding or cyclone events. Of particular note was the shift from spatial to stock entitlements in the Marine Aquarium Fishery that enabled fishers to relocate fishing grounds but, in return, reduce harvesting pressure on key functional herbivore species in response to bleaching events. Despite some progress, participants emphasised that more flexibility was needed (rapid adaptation responses to bleaching events, cyclones, and predation outbreaks are posited under ideal adaptation in $1 b$ and $2 b$ ).

Perspectives on Adaptation in the Fishing Industry

The GBR fishing industry is comprised of a range of commercial fisheries, including the East-Coast Otter Trawl Fishery, Coral Reef Finfish ('Reef Line') Fishery, East Coast Inshore Finfish ('Inshore Net') Fishery, and others, as well as a charter and a recreational line fishery. Participants discussed the potential of a range of adaptation strategies, most importantly business planning (e.g., financial management, networking, and marketing) and environmental stewardship (e.g., adopting, monitoring, and communicating sustainable activities), to deliver desirable outcomes, which they identified as: economic viability; environmental sustainability; and enjoyment (associated with recreational activities and the lifestyle values of commercial reefbased industries). Participants argued that those in the commercial fishing sector most adept at business planning ${ }^{3}$ were more profitable, less vulnerable, and more able to adapt to change than those who identify more closely with being a fisher than a business owner. However, participants stressed that the viability of the fishing sectors as a whole relied on adaptation among the entire cross-section of operators. As a result, current fisheries management and adaptation planning aim to furnish all operators with enhanced business skills and information in contexts of change. Similarly, government agencies and industry representative organisations provide information, technical assistance, and financial support to enable operators to improve their stewardship credentials and associated market share, a key example of which is the Reef Guardian Fishers programme (http:// www.gbrmpa.gov.au/our-partners/reef-guardians/reef-guardianfishers). Participants acknowledged the considerable progress made in terms of stewardship and sustainability and the continued opportunity to leverage a market advantage through green, organic, and buy-local marketing strategies considered essential to counter declining profitability as prices stagnate or decline through globalisation, market integration and competition, and as costs increase, particularly energy costs.

Other adaptation strategies were also viewed as processes that do or should occur at the industry level. Both the organisational structure and capacity of particular sectors were certainly factors beyond the influence of individual operators. In response to the scenarios, participants identified some key areas of convergence and also concern. For example, participants noted that fishing sectors on the east coast of Queensland were not currently amalgamating into international conglomerates (2a - Coastal Calamity) but that a few northern Australian fisheries were beginning to, driven by high value seafood rather than climate change. Participants suggested that while this could

\footnotetext{
${ }^{3}$ Entrepreneurs were not necessarily associated with larger businesses.
} 
improve efficiency in times of stability, it reduced the adaptive capacity of individual participating owner operators. These conglomerates were also perceived to possess fewer stewardship values than independent owner operators. Alternatively, organisation into co-operative structures, industry associations, and networks $(2 \mathrm{~b}$ - Volatile Waters) was perceived to facilitate spread of innovation and effective adaptation. However, it was noted that sectors and individuals varied and that a range of organisational and business models was needed to accommodate changing circumstances, preferences, and capabilities.

The management of effort within fishing sectors suggested in the scenarios was also an area of contention, in particular the permanent removal of effort and capacity from commercial sectors $(2 \mathrm{~b}$ - Volatile Waters). Fisheries buy-backs of quota or effort units and, in some cases, vessels and infrastructure have been undertaken in a number of Australian fisheries since the late 1990s (e.g., ECTF 2004). Participants identified three models of fishery buy-back schemes: full government funding; government loans to industry and industry co-operative funding. They also noted that buy-back schemes typically occurred under a sustainability banner, but were needed to address declining profitability. In general, buy-back processes have had mixed results with some failing to effectively minimise environmental impact and the social costs to operators exiting the industry. Generally, participants consider buy-back schemes as more or less appropriate depending on: i) the concentration of effort within individual fisheries - the more concentrated the effort, the higher the likelihood of effective effort reduction; ii) the value of the seafood commodity targeted - the higher the value the more potential for increased profits with fewer operators, and; iii) the nature of resource allocation in the fishery - in some sectors catch is not necessarily constrained by competition with other operators for limited resources. Legitimacy in buyback schemes was improved when industry associations could manage the funds allocated.

Participants noted that organisation into representative associations and networks, co-ordinated management of capacity, and demonstrated stewardship of the reef could also benefit the recreational fishing sector by enhancing its legitimacy and thereby its participation in, and influence of, mainstream management and adaptation planning processes. However, to date, the sector struggles with membership, representation and co-ordination of a large number of recreational fishers. As a result, representatives argue that they are not yet sufficiently consulted in policy and management decision-making, although this is improving.

Perspectives on Adaptation in the Reef-based Tourism Industry

Our data suggest that the tourism industry shares many commonalities with the fishing industry. First, they are both exposed to a range of climatic and non-climatic perturbations from which insight can be drawn about management and adaptation to climate change. Second, management of both sectors accounts for many types of disturbance; climate change is not considered separate. Third, representative stakeholders valued business planning and stewardship as key adaptation strategies, and considered networking and linking through representative organisations as beneficial for adaptive capacity $(1 \mathrm{~b}-$ Reef Relief and $2 \mathrm{~b}-$ Volatile Waters).

In contrast to the fishing industry, participants did not consider permanent removal of effort/capacity nor migration/ mobility as viable strategies for the reef-based tourism industry (contradicting $1 \mathrm{~b}$ and $2 \mathrm{~b}$ ). Existing reef-based tourism hubs stretching along the GBR from north to south, including Cairns, Port Douglas, and the Whitsundays will likely remain the core centres for marine tourism regardless of the impacts of climate change. Therefore, financial management, diversification, and marketing to create resilient businesses and communities that benefit from but do not overly depend on reefbased tourism are critical.

Participants identified marketing and communication campaigns as central to effective adaptation (not explicitly reflected in the scenarios) first, to ensure that customer expectations shift alongside changes to marine and coastal ecosystems, and; second to ensure that the comparative advantage of the GBR relative to other regions and reefs around the world is recognised. These campaigns relate to the long-term and short-term reputation of the reef. For instance, since 2006 representative organisations have promoted the reef as "the best managed reef in the world." In partnership with reef management agencies and scientists, they also disseminate up-to-date information packs globally, following surprise events such as cyclones and floods:

\section{Every time something physically blows up here we just send it [the statistics] all back to our American and British staff to say: 'Yes there was a cyclone. Yes this part of the reef has been severely damaged. But, it's actually 1/20th of the entire reef size and we don't go there anyway'... We work really closely with [the man- agement agency] to make sure we've got that sort of messaging.}

(Industry representative, March 2011)

This proactive marketing underpins other adaptation strategies including business planning and diversification at individual operator and industry level (scenarios $1 \mathrm{~b}$ and $2 \mathrm{~b}$ ). At the industry level examples include diversifying into interand intra-state tourism and developing new tourist attractions like the 'Great Eight' to parallel the 'Big Five' in terrestrial wildlife tourism. At the individual operator level, perceived opportunities to diversify were often linked to stewardship practices, for instance eco-tourism, accreditation, and uptake 
of green technologies. Reflecting the fishing industry discussion, participants perceived that tourism entrepreneurs and innovators - as those most likely to take risks and adapt through green technology and other strategies - were also most likely to remain profitable. However, the high turn-over of businesses in tourism and the challenge of achieving return on investment in an insecure global context mean that the level of capital investment needed to diversify is often prohibitive. Participants suggested that only a relatively small number of innovators could manage this risk and successfully leverage financial and technical support through their networks with government and representative industry associations.

Overall, recent experiences of composite perturbation suggest that while temporary, unexpected threats can be easily buffered and adapted to by individual operators, prolonged exposure to economic and climate risk are highly problematic for the industry.

\section{Discussion: Responding to Scenarios in Adaptation Research}

We developed scenarios to elicit diverse perspectives on climate change adaptation under a range of possible ecological and social impacts. Below, we discuss three key insights that influenced how stakeholders responded to the scenarios, and thus, their utility as a research tool. First, climate change impacts are still contested, so influencing how participants engage with representations of potential futures. Second, climate change impacts are perceived as relative, so scenarios for the GBR are not considered in isolation. Third, overall outcomes for people and industries are a culmination of vulnerabilities to climate change and other drivers. In some cases a climate change lens can strengthen and in other instances detract from wider debates on regional and national environment and development policy.

Our scenarios assume that anthropogenic climate change is happening but explore both a best-case and worst-case situation to accommodate for diverging perspectives on rates and impacts of change. Most stakeholder representatives accepted that change is happening and that adaptation is needed, regardless of attribution. But they differed in their emphasis on climate change as risk or opportunity, and some criticised the scenarios as being 'overly' negative. The scenarios posit that climate change introduces more risk than opportunity but that how this risk is managed is the key to creating opportunities. So opportunities are more likely to emerge from adaptation action than directly from climate change impacts. Research increasingly recognises that adaptation outcomes are a significant influence on people's wellbeing (Eriksen and Brown 2011; Marino and Ribot 2012) and are often more important than direct impacts (Eide and
Heen 2002). Such opportunities are reflected in the contrast between the Reef Relief (1b) and Paradise Perturbed (1a) scenarios. In the former - supported by participants - effective adaptation can improve on current trends in environmental change. In the latter, adaptation limited by ecological, institutional and economic factors fails to mediate change in quality, composition, and distribution of reef and coastal habitat or decline in habitat-associated species and biodiversity. This latter scenario does not make judgements about the social acceptability of such change nor does it intend to reflect the status quo in GBR management. Instead, the contrast of limited and ideal adaptation aims to highlight the opportunity cost of not pursuing more 'transformative' adaptation policy (Park et al. 2012), acknowledging that it will create winners and losers within and outside of reef industries (Marino and Ribot 2012).

The alternative scenarios aimed to represent a reasonable amount of complexity by accounting for drivers external to the reef and its industries, such as run-off impacts. However, the storylines did focus solely on the GBR meaning that the primary point of reference to qualitatively evaluate the scenarios is the current state of the reef. Consequently, participants were somewhat uncomfortable considering limited adaptation scenarios because they purposefully reflected a worst-case situation as opposed to current practice. Scenario planning methods often emphasise a set of quality criteria for scenarios, for instance, whether they are relevant, plausible, clear, and challenging (Kahane 2012). To elicit a broader range of stakeholder perspectives on ecological and social change, our scenarios purposefully contrasted extreme situations in terms of climate change trends and potential adaptation. As a result, while challenging, the relevance of these scenarios for GBR stakeholders (as opposed to scientists) was sometimes questioned.

Discussion also revealed that the outcomes for reef industries were not only dependent on responses in the GBR region but also management and adaptation elsewhere, particularly in competing markets. The clearest illustration of this came when we asked participants about the World Heritage status of the GBR under the more extreme climate change scenarios. Even under more extreme climate change with limited adaptation (scenario 2a), participants argued that other regions would suffer more impacts than the GBR, which was buffered by its history of effective management, and would not lose its World Heritage status. Indeed, many of the opportunities identified by participants related to the GBR's resilience and appeal relative to other destinations. For example, fisheries with reduced productivity might still increase in market share as other global fisheries collapsed. Similarly, tourism numbers could be maintained as other destinations suffered more extreme climate change impacts. This is supported by research suggesting that tourism is closely linked to perceptions of risk and impacts rather than real levels of risk or 
the actual state of the environment (McClanahan and Cinner 2012). While other regions may fare worse, opportunities for GBR stakeholders can nevertheless be maximised by effective adaptation of the fishing and tourism industries through the strategies discussed above, such as business planning, marketing, and diversification.

Participants emphasised that climate change adaptation is viewed as an integral part of overall enterprise and ecosystem management not as a separate agenda. There is some concern among stakeholders that the political interest in climate change and the financing attached to it could detract from the fundamentals of coastal and marine resilience, described as biodiversity, sustainability, water quality, and coastal development. To this end, participants argued that climate change should be incorporated into these policy arenas, rather than representing the overarching policy issue. Many of the insights shared by participants related to experiences of adaptation to other drivers of change. Maintaining a broad agenda can ensure inclusion of stakeholders who remain uncertain about the risks of climate change but who want to engage in broader processes of building adaptive capacity. At the same time, our findings suggest that climate change research further strengthens arguments to pursue sustainability and deal with coastal development and catchment land-use.

Overall, participants were more able to relate to the bestcase climate change scenarios than the more extreme scenarios. This is concerning considering the current emissions trajectories (Global Carbon Project 2010) but understandable given the uncertainty and differing perspectives around what society can achieve in the next 40 years. Regardless, both incremental (doing things better) and transformative (doing things differently) adaptation strategies were considered favourably. For instance, within the context of current fishing and reef-based tourism practices, participants discussed having the flexibility to move between heavily and lightly impacted sites following disturbance events, such as cyclones or bleaching. Participants also discussed strategies that move away from fishing and traditional reef-based tourism practices, such as skills training for fishers exiting the fishery, and even considered transformation of regional agricultural and coastal development policy.

\section{Conclusion}

Much of the literature on scenarios focuses on developing scenarios as the end point. Many studies conclude that involving stakeholders in the scenario development process can facilitate buy-in to complex environmental management and adaptation planning (Wollenberg et al. 2000; Tompkins et al. 2008; Cobb and Thompson 2012; Haward et al. 2012; Kahane 2012). Here, we developed comprehensive scenarios as a research tool to elicit data on adaptation experiences and expectations rather than an end product (see Fenton and Beedon 2006 and Daw et al. 2012 for use of more simple scenarios to frame research data collection). The scenarios developed in conjunction with scientists conveyed the range and complexity of possible change to the GBR and its fishing and tourism industries under a best-case and worst-case climate change future. They elicited a diversity of responses from multiple stakeholders in the region that contributed new and interesting insights into how adaptation is perceived. Stakeholders emphasised the inseparability of climate and other drivers of change, the importance of relative impacts, experiences, and outcomes, and the opportunities available from strategies such as business planning and stewardship, which are not typically considered in adaptation research.

We endeavoured to develop qualitative scenarios that reflected the complexity of interactions that constitute environmental and social change in the GBR region under a changing climate. For instance, we incorporated the impacts of catchment land-use and coastal development on water quality and ecological adaptation of coastal habitats. However, in practical terms, it was difficult to communicate the full extent of these scenarios to stakeholders in a workshop and interview setting (see Turton et al. 2010). Further, the complexity of the scenarios and/or the difficulty of situating responses in a future 'reality' considerably different from the present, limited the relevance (Kahane 2012) of the scenarios for GBR stakeholders and, therefore, the extent to which participants were able/willing to discuss adaptation to extreme climate change. Many of the responses were couched in localised, compositional change to the reef where climate change impacts were commensurate with other economic and regulatory drivers of change. Other research suggests that decision-support tools, and by extension research tools, may be more effective where they minimise 'cognitive complexity' for the decision-maker (see Tompkins et al. 2008). However, this negates to some extent the power and appeal of scenarios, which allow scientists, stakeholders, decision-makers, and others to explore complex combinations of drivers, choices and outcomes. From our experience, finding novel ways to communicate scenarios as part of a research or management process, through visual and audio tools, would overcome this tension and enhance the potential of scenarios to deliver important and insightful research and management outcomes.

Acknowledgements The authors would like to thank everyone who participated in this research project. The work was funded by the Australian Government and the partners in the National Climate Change Adaptation Research Facility (NCCARF) consortium. Human ethics approval for this research was obtained from James Cook University (H3808) and informed consent was provided by all research respondents. The views expressed herein remain the sole responsibility of the authors. 
Open Access This article is distributed under the terms of the Creative Commons Attribution License which permits any use, distribution, and reproduction in any medium, provided the original author(s) and the source are credited.

\section{References}

Adger, W. N., and Barnett, J. (2009). Four reasons for concern about adaptation to climate change. Environment and Planning A 41(12): 2800-2805.

Adger, W. N., Arnell, N. W., and Tompkins, E. L. (2005). Successful adaptation to climate change across scales. Global Environmental Change 15: 77-86.

Adger, W. N., Agrawala, S., Mirza, M. Q. Q., Conde, C., O’Brien, K., Pulhin, J., Pulwarty, R., Smit, B., and Takahashi, K. (2007). Assessment of adaptation practices, options, constraints and capacity. In Parry, M. L., Canziani, O. F., Palutikof, J. P., van der Linden, P. J., and Hanson, C. E. (eds.), Climate Change 2007: Impacts, Adaptation and Vulnerability. Contribution of Working Group II to the Fourth Assessment Report of the Intergovernmental Panel on Climate Change. Cambridge University Press, Cambridge, pp. 717-743.

Allison, E. H., Perry, A. L., Badjeck, M.-C., Adger, W. N., Brown, K., Conway, D., Halls, A. S., Pilling, G. M., Reynolds, J. D., Andrew, N. L., and Dulvy, N. K. (2009). Vulnerability of national economies to the impacts of climate change on fisheries. Fish and Fisheries 10: 173-196.

Anthony, K. R. N., Maynard, J. A., Diaz-Pulido, G., Mumby, P. J., Marshall, P. A., Cao, L., and Hoegh-Guldberg, O. (2012). Ocean acidification and warming will lower coral reef resilience. Global Change Biology 17(5): 1798-1808.

Baskett, M. L., Gaines, S. D., and Nisbet, R. M. (2009). Symbiont diversity may help coral reefs survive moderate climate change. Ecological Applications. Ecological Applications 19(1): 3-17.

Bjarnadottir, S., Li, Y., and Stewart, M. G. (2011). Social vulnerability index for coastal communities at risk to hurricane hazard and a changing climate. Natural Hazards 59: 1055-1075.

Bohensky, E., Butler, J., Costanza, R., Bohnet, I., Delislee, A., Fabricius, K., Gooch, M., Kubiszewskic, I., Lukacsh, G., Pert, P., and Wolanski, E. (2011). Future makers or future takers? A scenario analysis of climate change and the Great Barrier Reef. Global Environmental Change 21: 876-893.

Bohnet, I., Bohensky E., Gambley C., and Waterhouse J., (2008). Future scenarios for the Great Barrier Reef Catchment. Final Project Report. CSIRO. Water for a Health Country National Research Flagship. pp 56.

Brundell, J., Cobon, D., Stone, G., and Cliffe, N., 2010 Climate change risk management matrix: a process for assessing impacts, adaptation, risk and vulnerability. Workbook. Queensland Climate Change Centre of Excellence (QCCCE) Department of Environment and Resource Management. 21pp

Cinner, J. E., McClanahan, T. R., Graham, N. A. J., Daw, T. M., Maina, J., Stead, S. M., Wamukota, A., Brown, K., and Bodin, O. (2012). Vulnerability of coastal communities to key impacts of climate change on coral reef fisheries. Global Environmental Change 22: 12-20.

Crabbe, M. J. C. (2009). Modelling effects of geoengineering options in response to climate change and global warming: Implications for coral reefs. Computational Biology and Chemistry 33: 415-420.

Council of Australian Governments (COAG). (2009). National Strategy for Disaster Resilience. Canberra. [online]. Available from: http://www. coag.gov.au/sites/default/files/national_strategy_disaster_resilience.pdf [accessed 20.03.13].

Cobb, A. N., and Thompson, J. L. (2012). Climate change scenario planning: a model for the integration of science and management in environmental decision-making. Environmental Modelling \& Software 38: 296-305.

Daw, T. M., Cinner, J. E., McClanahan, T. R., Brown, K., Stead, S. M., Graham, N. A. J., and Maina, J. (2012). To Fish or Not to Fish: Factors at Multiple Scales Affecting Artisanal Fishers' Readiness to Exit a Declining Fishery. PLoS ONE 7(2): e31460 doi:10.1371/ journal.pone. 0031460 .

De'ath, G., Lough, J., and Fabricius, K. E. (2009). Declining coral calcification on the Great Barrier Reef. Science 323(5910): 116-119.

De'ath, G., and Fabricius, K. (2010). Water quality as a regional driver of coral biodiversity and macroalgae on the Great Barrier Reef. Ecological Applications 20: 840-850.

Department of Environment and Resource Management (DERM). (2012). The Queensland Coastal Plan. State of Queensland. [online]. Available from: http://www.ehp.qld.gov.au/coastalplan/pdf/ qcp-web.pdf [accessed 20.03.13].

East Coast Trawl Fishery, (2004). Review of the sustainability of fishing effort in the Queensland East Coast Trawl Fishery. (Eds) Kerrigan, B., Gaddes, S., Norris, W. Queensland Government Department of Primary Industries and Fisheries. 221 pp.

Eberhard, R., Robinson, C. J., Waterhouse, J., Parslow, J., Hart, B., Grayson, R., and Taylor, B. (2009). Adaptive management for water quality planning - from theory to practice. Marine and Freshwater Research 60: 1189-1195.

Edwards, H. J., Elliott, I. A., Eakin, C. M., Irikawa, A., Madin, J. S., McField, M., Morgan, J. A., van Woesik, R., and Mumby, P. J. (2011). How much time can herbivore protection buy for coral reefs under realistic regimes of hurricanes and coral bleaching? Global Change Biology 17(6): 2033-2048.

Eide, A., and Heen, K. (2002). Economic impacts of global warming. A study of the fishing industry in North Norway. Fisheries Research 56: $261-274$.

Eriksen, S., and Brown, K. (2011). Sustainable adaptation to climate change. Climate and Development 3(1): 3-6.

Fenton, M., and Beedon, R., (2006) Stakeholder beliefs about climate change in the Great Barrier Reef Catchment. Report Prepared for: Great Barrier Reef Marine Park Authority. 51pp

Fulton, E. A. (2011). Interesting times: winners, losers, and system shifts under climate change around Australia. ICES Journal of Marine Science 68(6): 1329-1342.

Gillson, J. (2011). Freshwater flow and fisheries production in estuarine and coastal systems: where a drop of rain is not lost. Reviews in Fisheries Science 19(3): 168-186.

Gilman, E. L., Ellison, J., Duke, N. C., and Field, C. (2008). Threats to mangroves from climate change and adaptation options: A review. Aquatic Botany 89: 237-250.

Global Carbon Project. (2010). http://www.globalcarbonproject.org/ carbonbudget/index.htm

Graham, N. A. J., Wilson, S. K., Jennings, S., Polunin, N. V. C., Bijoux, J. P., and Robinson, J. (2006). Dynamic fragility of oceanic coral reef ecosystems. Proceedings of the National Academy of Sciences of the United States of America. 103(22): $8425-8429$.

Graham, N. A. J., Wilson, S., Jennings, S., Polunin, N., Robinson, J., Bijoux, J., and Daw, T. (2007). Lag effects in the impacts of mass coral bleaching on coral reef fish, fisheries, and ecosystems. Conservation Biology 21: 1291-1300.

Graham, N. A. J., McClanahan, T. R., MacNeil, M. A., Wilson, S. K., Polunin, N. V. C., Jennings, S., Chabanet, P., Clark, S., Spalding, M. D., Letourneur, Y., Bigot, L., Galzin, R., Ohman, M. C., Garpe, K. C., Edwards, A. J., and Sheppard, C. R. C. (2008). Climate warming, marine protected areas and the ocean-scale integrity of coral reef ecosystems. PloS One 3: e3039.

Great Barrier Reef Marine Park Authority (2009a). Great Barrier Reef outlook report 2009. Great Barrier Reef Marine Park Authority, Townsville. 
Great Barrier Reef Marine Park Authority. (2009b). Tourism Climate Change Action Strategy 2009-2012. Tackling climate change [online]. Available from:/http://www.gbrmpa.gov.au/our-partners/ tourism-industry/tackling-climate-change [accessed 20.03.13].

Gunn, J., Fraser, G., and Kimball, B., (2010). Review of the Great Barrier Reef Marine Park Structural Adjustment Package. Report for the Department of Environment, Water, Heritage and the Arts (DEWHA). $129 \mathrm{pp}$

Haward, M., Davidson, J., Lockwood, M., Hockings, M., Kriwoken, L., and Allchin, R., (2012). Climate change, scenarios and marine biodiversity conservation. Marine Policy. doi.org/10.1016/j.marpol.2012.07.004

Hobday, A. J. (2011). Sliding baselines and shuffling species: implications of climate change for marine conservation. Marine Ecology 32: $392-403$

Hobday, A. J., Okey, T. A., Poloczanska, E. S., Kunz, T. J., and Richardson, A. J. (eds.) (2006). Impacts of climate change on Australian marine life: Part C. Literature Review. Report to the Australian Greenhouse Office, Canberra, Australia.

Hobday, A. J., Poloczanska, E. S., and Matear, R. J. (eds.) (2008). Implications of Climate Change for Australian Fisheries and Aquaculture: a preliminary assessment. Report to the Department of Climate Change, Canberra, Australia.(August 2008).

Hoegh-Guldberg, O. (1999). Climate change, coral bleaching and the future of the world's coral reefs. Mar. Freshwater Res. 50: 839-866.

Hoegh-Guldberg, H., and Hoegh-Guldberg, O. (2004). The Implications of Climate Change for Australia's Great Barrier Reef: People and Industries at Risk. World Wildlife Fund and Queensland Tourism Industry. Council, Brisbane.

Hoegh-Guldberg, O., and Bruno, J. F. (2010). The Impact of Climate Change on the World's Marine Ecosystems. Science: 1523-1528.

Hoegh-Guldberg, O., Mumby, P. J., Hooten, A. J., Steneck, R. S., Greenfield, P., Gomez, E., Harvell, C. D., Sale, P. F., Edwards, A. J., Caldeira, K., Knowlton, N., Eakin, C. M., Iglesias-Prieto, R., Muthiga, N., Bradbury, R. H., Dubi, A., and Hatziolos, M. E. (2007). Coral reefs under rapid climate change and ocean acidification. Science 318: 1737-1742.

Hughes, T. P., Baird, A. H., Bellwood, D. R., Card, M., Connolly, S. R., Folke, C., Grosberg, R., Hoegh-Guldberg, O., Jackson, J. B. C., Kleypas, J., Lough, J. M., Marshall, P., Nyström, M., Palumbi, S. R., Pandolfi, J. M., Rosen, B., and Roughgarden, J. (2003). Climate Change, Human Impacts, and the Resilience of Coral Reefs. Science. 929-933.

Hughes, T. P., Graham, N. A. J., Jackson, J. B. C., Mumby, P. J., and Steneck, R. S. (2010). Rising to the challenge of sustaining coral reef resilience. Trends in Ecology and Evolution 25(11): 633-642.

Hulme, M., and Dessai, S. (2008). Predicting, deciding, learning: can one evaluate the 'success' of national climate scenarios? Environmental Research Letters 3(045013): 1-7.

IPCC (2000). Special report on emissions scenarios. Intergovernmental Panel on Climate Change. Cambridge University Press, Cambridge.

IPCC $4^{\text {th }}$ Assessment. Nicholls, R. J., Wong, P. P., Burkett, V. R., Codignotto, J. O., Hay, J. E., McLean, R. F., Ragoonaden S., and Woodroffe, C. D., (2007). Coastal systems and low-lying areas. Climate Change 2007: Impacts, Adaptation and Vulnerability. Contribution of Working Group II to the Fourth Assessment Report of the Intergovernmental Panel on Climate Change, M.L. Parry, O.F. Canziani, J.P. Palutikof, P.J. van der Linden and C.E. Hanson, Eds., Cambridge University Press, Cambridge, UK, 315-356.

Johnson, J. E., and Marshall, P. A. (2007). The Great Barrier Reef and climate change: vulnerability and management implications. In Climate change and the Great Barrier. Reef - a vulnerability assessment. Great Barrier Reef Marine Park Authority and the Australian Greenhouse Office, Australia.

Johnson, K. A., Dana, G., Jordan, N. R., Draeger, K. J., Kapuscinski, A., Schmitt Olabisi L, K., and Reich, P. B., (2012). Using participatory scenarios to stimulate social learning for collaborative sustainable development. Ecology and Society 17(2): 9. http:// dx.doi.org/10.5751/ES-04780-170209

Kahane, A. (2012). Working together to change the future: Transformative scenario planning. Berrett-Koehler Publishers Inc, San Francisco, USA.

Lédée, E. J. I., Sutton, S. G., Tobin, R. C., and DeFreitas, D. M. (2012). Responses and adaptation strategies of commercial and charter fishers to zoning changes in the Great Barrier Reef Marine Park. Marine Policy 36: 226-234.

Lough, J. (2007). Climate and climate change on the Great Barrier Reef. In Climate change and the Great Barrier. Reef - a vulnerability assessment. Great Barrier Reef Marine Park Authority and the Australian Greenhouse Office, Australia.

Lough, J. M., (2012). Small change, big difference: Sea surface temperature distributions for tropical coral reef ecosystems, 1950 2011. Journal of Geophysical Research. 117: doi:10.1029/ 2012JC008199, 2012

McKinnon, A. D., Richardson, A. J., Burford, M. A., and Furnas, M. J. (2007). Vulnerability of Great Barrier Reef plankton to climate change. In Climate change and the Great Barrier. Reef - a vulnerability assessment. Great Barrier Reef Marine Park Authority and the Australian Greenhouse Office, Australia.

Marino, E., and Ribot, J. (2012). Adding insult to injury: Climate change and the inequities of climate intervention. Global Environmental Change 22: 323-328.

Marshall, P., and Marshall, N. (2012). Extreme weather: adaptation insights from the Great Barrier Reef. Prepared for NCCARF, Marine.

McClanahan, T. R., and Cinner, J. E. (2012). Adapting to a changing environment: confronting the consequences of climate change. Oxford University Press, New York.

McClanahan, T. R., Cinner, T. E., Maina, J., Graham, N. A. J., Daw, T. M., Stead, T. M., Wamukota, A., Brown, K., Ateweberhan, M., Venus, V., and Polunin, N. V. C. (2008). Conservation action in a changing climate. Conservation Letters. 1: 53-59.

McCulloch, M., Fallon, S., Wyndham, T., Hendy, E., Lough, J., and Barnes, D. (2003). Coral record of increased sediment flux to the inner Great Barrier Reef since European settlement. Nature 421: 727-730.

Millennium Ecosystem Assessment (2005a). Current state and trends assessment: coastal systems. Island Press, Washington DC. pp 37.

Millennium Ecosystem Assessment (2005b). Ecosystems and human well-being: scenarios. Findings of the Scenarios Working Group. Carpenter, S, R., et al. (Editors). Island Press, Washington. pp 72.

Miller, G. M., Watson, S. A., Donelson, J. M., McCormick, M. I., and Munday, P. L. (2012). Parental environment mediates impacts of increased carbon dioxide on a coral reef fish. Nature Climate Change doi:10.1038/NCLIMATE1599.

Mumby, P. J., Dahlgren, C. P., Harborne, A. R., Kappel, C. V., Micheli, F., Brumbaugh, D. R., Holmes, K. E., Mendes, J. M., Broad, K., Sanchirico, J. N., Buch, K., Box, S., Stoffle, R. W., and Gill, A. B. (2006). Fishing, trophic cascades and the process of grazing on coral reefs. Science 311(5757): 98-101.

Munday, P. L., Jones, G. P., Pratchett, M. S., and Williams, A. J. (2008). Climate change and the future for coral reef fishes. Fish and Fisheries 9: 261-285.

Munday, P. L., Dixson, D. L., Donelson, J. M., Jones, G. P., Pratchett, M. S., Devitsina, G. V., and Doving, K. B. (2009). Ocean acidification impairs olfactory discrimination and homing ability of a marine fish. Proc Nat Acad Sci 106(6): 1848-1852.

Nilsson, G. E., Dixson, D. L., Domenici, P., McCormick, M. I., Sørensen, C., Watson, S-A., and Munday, P. L., (2012). Nearfuture carbon dioxide levels alter fish behaviour by interfering with neurotransmitter function. Nature Climate Change. 1352. DOI: 10.1038 /NCLIMATE1352

Pandolfi, J. M., Connolly, S. R., Marshall, D. J., and Cohen, A. L. (2011). Acidification Projecting Coral Reef Futures Under Global Warming and Ocean. Science 333: 418. 
Park, S. E., Marshall, N. A., Jakku, E., Dowd, A. M., Howden, S. M., Mendham, E., and Fleming, A. (2012). Informing adaptation responses to climate change through theories of transformation. Global Environmental Change 22: 115-126.

Pereira, H. M., Leadley, P. W., Proença, V., Alkemade, R., Scharlemann, J. P. W., Fernandez-Manjarrés, J. F., Araújo, M. B., Balvanera, P., Biggs, R., Cheung, W. W. L., Chini, L., Cooper, H. D., Gilman, E. L., Guénette, S., Hurtt, G. C., Huntington, H. P., Mace, G. M., Oberdorff, T., Revenga, C., Rodrigues, P., Scholes, R. J., Sumaila, U. R., and Walpole, M., (2010). Scenarios for Global Biodiversity in the 21st Century. Science: 1496-1501

Perry, A. L. L., Ellis, P. J., and Reynolds, J. D. (2005). Climate change and distribution shifts in marine fishes. Science 308: 1912-1915.

Pratchett, M. S., Munday, P. L., Wilson, S. K., Graham, N. A. J., Cinner, J. E., Bellwood, D. R., Jones, G. P., Polunin, N. V. C., and McClanahan, T. R. (2008). Effects of climate induced coral bleaching on coral-reef fishes - ecological and economic consequences. Oceanography and Marine Biology: An Annual Review 2008(46): 251-296.

QCCCE, n.d. Queensland Regional Climate Projections. Accessed 29 May 2011. http://www.climatechange.qld.gov.au/whatsbeingdone/ climatechangestrategy/impactsonqueenslandsregions.html

Robins, J. B., Halliday, I. A., Staunton-Smith, J., Mayer, D. G., and Sellin, M. J. (2005). Freshwater-flow requirements of estuarine fisheries in tropical Australia: A review of the state of knowledge and application of a suggested approach. Mar. Freshw. Res 56: 343-360.

Sweatman, H., Delean, S., and Syms, C. (2011). Assessing loss of coral cover on Australia's Great Barrier Reef over two decades, with implications for longer-term trends. Coral Reefs 30: 521-531.

Thomas, C. R., Gordon, I. J., Wooldridge, S., and Marshall, P. (2012). Balancing the Tradeoffs between Ecological and Economic Risks for the Great Barrier Reef: A Pragmatic Conceptual Framework. Human and Ecological Risk Assessment 18: 69-91.

Tobin, A., Schlaff, A., Tobin, R., Penny, A., Ayling, T., Ayling, A., Krause, B., Welch, D., Sutton, S., Sawynok, B., Marshall, N., Marshall, P., and Maynard, J., (2010). Adapting to change: minimising uncertainty about the effects of rapidly-changing environmental conditions on the Queensland Coral Reef Fin Fish Fishery. Final Report to the Fisheries Research \& Development Corporation, Project 2008/103. Fishing and Fisheries Research Centre Technical Report No. 11, James Cook University, Australia pp 1-172.
Traill, L. W., Perhans, K., Lovelock, C. E., Prohaska, A., McFallan, S., Rhodes, J. R., and Wilson, K. A. (2011). Managing for change: wetland transitions under sea-level rise and outcomes for threatened species. Diversity and Distributions 17: 1225-1233.

Tompkins, E. L., Few, R., and Brown, K. (2008). Scenario-based stakeholder engagement: Incorporating stakeholders preferences into coastal planning for climate change. Journal of Environmental Management 88(4): 1580-1592.

Turton, S., Dickson, T., Hadwen, W., Jorgensen, B., Pham, T., Simmons, D., Tremblay, P., and Wilson, R. (2010). Developing an approach for tourism climate change assessment: evidence from four contrasting Australian case studies. Journal of Sustainable Tourism 18(3): 429-447.

Wachenfeld, D., Johnson, J., Skeat, A., Kenchington, R., Marshall, P., and Innes, J. (2007). Introduction to the Great Barrier Reef and climate change. In Climate change and the Great Barrier Reef - a vulnerability assessment. Great Barrier Reef Marine Park Authority and the Australian Greenhouse Office, Australia.

Waycott, M., Duarte, C. M., Carruthers, T. J. B., Orth, R. J., Dennison, W. C., Olyarnik, S., Callandinea, A., Fourqureanf, J. W., Heck, K. L., Hughes, A. R., Kendrick, G. A., Kenworthy, W. J., Short, F. T., and Williams, S. L. (2009). Accelerating loss of seagrasses across the globe threatens coastal ecosystems. PNAS 106(30): 12377-12381.

Wilby, R., and Dessai, S. (2010). Robust adaptation to climate change. Weather 65(7): 180-185.

Wilson, S. K., Dolman, A. M., Cheal, A. J., Emslie, M. J., Pratchett, M. S., and Sweatman, H. P. A. (2009). Maintenance of fish diversity on disturbed coral reefs. Coral Reefs 28: 3-14.

Wollenberg, E., Edmunds, D., and Buck, L. (2000). Using scenarios to make decisions about the future: anticipatory learning for the adaptive co-management of community forests. Landscape and Urban Planning 47: 65-77.

Wooldridge, S. A. (2009). Water quality and coral bleaching thresholds: Formalising the linkage for the inshore reefs of the Great Barrier Reef, Australia. Marine Pollution Bulletin 58(5): 745-751.

Wooldridge, S. A., Done, T. J., Thomas, C. E., Gordon, I. I., Marshall, P. A., and Jones, R. N. (2012). Safeguarding coastal coral communities on the central Great Barrier Reef (Australia) against climate change: realizable local and global actions. Climatic Change 112: 945-961.

Woolsey, E., Bainbridge, S. J., Kingsford, M. J., and Byrne, M. (2012). Impacts of cyclone Hamish at One Tree Reef: integrating environmental and benthic habitat data. Marine Biology 159(4): 793-803. 